\title{
IMPLICAÇÕES DA ECONOMIA POPULAR SOLIDÁRIA NA FORMAÇÃO DOS SUJEITOS DA INICIATIVA DESSA ECONOMIA NA UNIVERSIDADE ESTADUAL DE FERIA DE SANTANA
}

\author{
Paloma Amorim de Brito ${ }^{1}$ \\ José Raimundo Oliveira Lima ${ }^{2}$
}

Palavras-Chave: Educação e trabalho; Formação; Economia popular solidária.

\section{INTRODUÇÃO}

O tema Economia Solidária, em seu caráter popular, compreendido como ato pedagógico, vem sendo problematizado e discutido por diversos autores, dentre eles Gadotti (2009) e Melo Neto (2006). Trata-se de questão primordial para o trabalho realizado pela Incubadora de Iniciativas da Economia Popular Solidária (IEPS), da Universidade Estadual de Feira de Santana (UEFS), que se volta para o trabalho desenvolvido sob os princípios cooperativo, solidário, associativo e autogestionário, trazendo em sua carta de princípios, a relação trabalho-educação como base fundamental dos processos educativos populares.

Este estudo surge da necessidade de refletir o processo educativo em que consiste o trabalho compartilhado pelos/as participantes dos grupos em processo de incubação e o programa IEPS-UEFS, contribuindo na sua formação, a partir da compreensão do trabalho como "um processo entre o homem e a natureza, um processo em que o homem, por sua própria ação, media, regula e controla seu metabolismo com a natureza" (MARX, 1996, p. 297).

Assim, constitui-se o objetivo central deste estudo - de modo a contribuir com o desenvolvimento da reflexão, da produção de conhecimento, da autonomia e da criticidade no âmbito da graduação - tecer reflexões sobre as implicações do trabalho, como ato educativo humanizado, na formação dos sujeitos trabalhadores das iniciativas populares que participam dos processos de incubação desenvolvidos IEPS - UEFS e analisar sobre como se dá o diálogo entre os conhecimentos científicos e empíricos dos sujeitos.

Corroborando com Lima (2010, p. 3) a economia popular e solidária articulada com a educação popular, constitui-se

uma dimensão indispensável à politização, ao empoderamento, ao desfazimento das relações impostas pelo contrato social moderno e, em especial, da conscientização sobre a importância do trabalho como elemento central e político para um processo histórico, dialético.

Assim, Melo Neto (2006) salienta que a economia popular e solidária tem a intencionalidade de assegurar condições de sobrevivência e qualidade de vida aos trabalhadores e trabalhadoras à margem da riqueza social, com princípios definidos em vários encontros, que são: a valorização social do trabalho humano, a satisfação das necessidades de todos os eixos da criatividade tecnológica e da atividade econômica, os valores de cooperação e solidariedade,

\footnotetext{
${ }^{1}$ Bolsista do PROBIC/UEFS, graduanda em Licenciatura em Pedagogia, Universidade Estadual de Feira de Santana, e-mail: paotirb@gmail.com

${ }^{2}$ Orientador, Professor do Departamento de Ciências Sociais Aplicadas, Universidade Estadual de Feira de Santana, e-mail: joseraimundouefs@ hotmail.com
} 
a busca de uma relação respeitosa com a natureza e o reconhecimento do lugar da mulher e do feminino numa economia fundada na solidariedade.

Destarte, consideramos de grande importância social o desenvolvimento deste estudo, visto que, a compreensão das especificidades e dos elementos que cercam a prática pedagógica, instigando a discussão de aspectos que têm sido marginalizados no atual cenário das pesquisas em educação.

\section{METODOLOGIA}

Este estudo de caráter qualitativo foi realizada na cantina do Módulo I, da UEFS, tendo como objeto de investigação a formação humana, emancipatória, através do trabalho realizado na cantina. Para tanto, a pesquisadora se valeu, igualmente, da observação dos processos de incubação desenvolvidos pela IEPS-UEFS, participando de suas reuniões, Grupo de Estudos e Pesquisas sobre Economia Popular e Solidária e Desenvolvimento Local Solidário (GEPOSDEL) e espaços de formações.

Utilizou-se também de levantamento bibliográfico, como suporte teórico sobre a temática, na qual diversos autores contribuíram como embasamento para pesquisa. Parte-se, na investigação da compreensão do ato de investigar e de buscar informações sobre determinado assunto, "sob um novo enfoque ou abordagem, chegando a conclusões inovadoras". (MARCONI E LAKATOS, 1999, p. 71). Nesse sentido, as reflexões sobre a economia popular e solidária e o trabalho desenvolvido pela IEPS, na ótica da educação popular, confirmam tal perspectiva inovadora.

A metodologia utilizada para realização dessa pesquisa se constitui na pesquisa participante, escolha feita inicialmente pelo grupo, por compreender a importância do diálogo na dinâmica da pesquisa. A produção dos dados foi através de observação, diálogos entre pesquisadora e sujeitos da pesquisa, em que a primeira apresentou aos sujeitos os objetivos da pesquisa na perspectiva de salientar a interação e proporcionar que os mesmos compreendam a relevância do projeto, os desafios e a contribuição desta pesquisa para a comunidade.

\section{RESULTADOS E/OU DISCUSSÃO (OU ANÁLISE E DISCUSSÃO DOS RESULTADOS)}

O Programa Incubadora de Iniciativas da Economia Popular e Solidária (IEPS) da UEFS, consolidado através da resolução CONSEPE 150/2010, vem implementando nos espaços da Cantina do Módulo VII, desde 2012, um projeto de Incubação de iniciativa da Economia Popular e Solidária que trabalha com a produção e comercialização de alimentos, sobretudo lanches e almoço.

Segundo Melo Neto, as incubadoras, configura-se em uma alternativa a um sistema que desfavorece os trabalhadores, implementam um modelo de ação ao combate ao desemprego e a exclusão social, promovendo ações de inserção social, numa perspectiva solidária. Assim muitos são os desafios das incubadoras, tanto de ordem financeira, quanto de recursos humanos.

Um dos grandes desafios encontrados da IEPS - UEFS se dá no diálogo com as cooperativas, que trazem consigo seus conhecimentos/ saberes enraizados e que, ao depararem com as burocratizações e normas da instituição, abalam-se. Segundo Singer (2002, p. 19) a economia solidária é um ato pedagógico em si mesmo, na medida em que propõe nova prática social e um entendimento novo dessa prática, "a única maneira de aprender a construir a Economia Solidária é praticando-a". Assim, ressalta-se a importância da articulação do saber popular com o conhecimento científico, a fim de valorizar esses saberes, e ampliar os horizontes desses sujeitos com o que se tem produzindo na universidade.

Os grupos que participam do processo de incubação buscam, de maneira associada, solidária e autogestionária a partir das atividades produzidas nas cantinas além fonte de renda 
para suas famílias, um espaço de trabalho justo. Neste sentido Melo Neto (2006) salienta que a economia popular e solidária tem a intencionalidade de assegurar condições de sobrevivência e qualidade de vida aos trabalhadores e trabalhadoras à margem da riqueza social.

A IEPS como um espaço, que materializa o desafio das universidades serem, flexíveis e "desverticalizadora", com a comunidade possibilita a discussão de elementos relativos à aprendizagem, tendo em vista suas diversidades de formas de ensinar e aprender, ultrapassando os muros das escolas, na realidade do cotidiano do/a trabalhador/a.

Os espaços de formações são momentos fundamentais para tanto para o grupo quanto para a incubadora, pois permite que os sujeitos se constituem em pessoas ativas no seu processo de produção, na ontologia do exercício da reflexão, desconstruindo as formas de compreensão do trabalho posta pelo capitalismo. Conforme Freire (1979, p. 21),

[...] no ato mesmo de responder aos desafios que lhe apresenta seu contexto de vida, o homem se cria, se realiza como sujeito, porque esta resposta exige dele reflexão, crítica, invenção, eleição, decisão, organização, ação...

Dessa maneira, reconhece-se enquanto sujeito está diretamente ligado à sua participação crítica socialmente atuante. Os sujeitos que participam do programa da IEPS, em sua maioria afastados do mercado formal, relatam em diversos momentos o quão impactante é tomar consciência do seu trabalho e a dificuldade de trabalhar de maneira autogestionária, sem a figura do "patrão". A trabalhadora Ana (nome fictício) relata que

a forma de dividir o trabalho é diferente de outras experiências que tive, tá sendo um trabalho prazeroso e estamos nos dando bem, mas é complicado essa questão que nós somos nossos patrões, mas temos que respeitar o outro pra o grupo andar.

Na fala, reconhecemos que há o reconhecimento do trabalho diferenciado desenvolvido pela IEPS, diferenciando da lógica capitalista do trabalho. E um desafio posto de desnaturalizar a visão do patrão como a figura de organizador, do quem media o respeito e faz a interlocução entre as relações interpessoais.

Destarte, na compreensão do trabalho como o ato educativo imbricado no seu desenvolvimento, na sua apropriação do conhecimento e na possibilidade de reconhecer-se enquanto produtores de sua história, rompendo a lógica alienante do trabalho.

De maneira geral, esses sujeitos são implicados nas formas de vida oriundas da relação/educação, cujas relações conduzem a sua existência em diversas dimensões da vida, seja política, social, econômica, ambiental, cultura e educacional.

$\mathrm{Na}$ perspectiva da educação popular, esta possibilita a busca de novos paradigmas e de ação político-pedagógica capaz de promover a reflexão da criticidade sobre o mundo e as relações humanas como expressão dialética para a transformação social, compreendendo a própria prática de suas formas de relacionamento com o outro humano, expressando posicionamentos políticos diante do mundo, voltado para os interesses da maioria dos trabalhadores e trabalhadoras. A partir das observações realizadas na cantina do módulo I, pode-se perceber que há superações, cotidianamente, dos/as participantes, na construção de hábitos que permita a efetivação dos princípios da economia solidária. Este processo educativo permite o empoderamento dos/as trabalhadores, fazendo-se reconhecer na arena política como interlocutores válidos e necessários (GOHN, 2012), com o objetivo de construir uma sociedade livre e solidário, que valorize os sujeitos. 


\section{CONSIDERAÇÕES FINAIS}

Esta pesquisa objetivou analisar as implicações da economia popular e solidária na formação dos sujeitos trabalhadores das iniciativas populares que participam dos processos de incubação desenvolvidos pela Incubadora de Iniciativas da Economia Popular Solidária da UEFS - IEPS-UEFS.

Na sociedade capitalista em que estamos inseridos, num cenário de desigualdade social, na qual a exploração e o individualismo são características marcantes, o trabalho é visto como uma obrigação, o que torna um grande desafio ir contra essa ótica e fomentar a necessidade de uma produção popular, visando um novo modo de produção pautado na integração entre os/as trabalhadores/as, no coletivo.

A economia popular e solidária é uma alternativa de vida mais justa, de melhores condições de trabalho. Compreender esta economia como ato educativo é de suma importância para a formação humana dos sujeitos, é um grande desafio. Articula-la com a educação popular fomenta a importância da participação ativa dos/as trabalhadores/as, a superação das desigualdades e o empoderamento político-cultural.

A economia popular e solidária vai além da concepção econômica englobando a dimensão social, cultural, política que resgata os valores como cooperação, colaboração, coletividade, contribuindo para a formação humana dos sujeitos. A educação, na perspectiva popular, entendida como amplos processos socioculturais na construção do saber, voltado para a valorização humana em busca da emancipação.

A incubadoras tem papel fundamental que qualifica o trabalho acadêmico, no exercício da pesquisa e extensão universitária, como um trabalho social, materializa um ambiente para a promoção das atividades associativas, autogestionárias.

Dessa maneira, os participantes do projeto vão gradualmente construindo e solidificando os princípios da economia solidária, fomentando a solidariedade, autogestão, coopertividade, se reconhecendo no processo do trabalho realizado.

\section{REFERÊNCIAS}

CRUZ, Antonio; GUERRA, Janaína da Silva. Educação popular e economia solidária nas incubadoras universitárias de cooperativas populares - práticas dialógicas mediadas pelo trabalho. In: HERBERT, Sérgio et al. Participação e práticas educativas - a construção coletiva do conhecimento. São Leopoldo: Oikós, 2009.

FREIRE, Paulo. Conscientização: teoria e prática da libertação: uma introdução ao pensamento de Paulo Freire. São Paulo: Cortez \& Moraes, 1979.

GOHN, Maria da Glória Marcondes. Movimentos sociais e educação. Cortez Editora, 1992. IEPS, Uefs. Projeto Incubadora Tecnológica de Cooperativas Populares da Universidade Estadual de Feira de Santana. Feira de Santana, 2009.

LIMA, j. R. O. A economia popular e solidária como possibilidade de política pública capaz de contribuir para o desenvolvimento local sustentável. In: Conferência Nacional de Políticas Públicas, 2010, Natal. I Conferência Nacional de Políticas Públicas. UFRN, 2010.

MARCONI, Marina de Andrade; LAKATOS, Eva Maria. Técnicas de pesquisa. São Paulo: Atlas, 1999.

MARX, Karl. O capital. Rio de Janeiro: Civilização Brasileira, 1974.

MELO NETO, José Francisco de. Educação popular em economia solidária. GT 06 Educação Popular. ANPED. 2006.

SINGER, Paul. Introdução à economia solidária. São Paulo: Fundação Perseu Abramo, 2002. 